\title{
As desigualdades escolares antes e depois da escola: organização escolar e influência dos diplomas.1.2
}

\author{
FRANGOIS DUBET" \\ MARIE DURU-BELLAT \\ ANTOINE VÉRÉTOUT ${ }^{* * a}$
}

\section{Resumo}

A escola reproduz as desigualdades sociais por ser mais favorável aos alunos social e culturalmente privilegiados. No entanto, essa "lei" é demasiado geral para explicar as grandes variações na amplitude dessa reprodução, reveladas pelas comparações internacionais. Partindo desses estudos, o artigo mostra, em primeiro lugar, que essas variações não se explicam diretamente pela amplitude das desigualdades sociais. Para explicá-las é preciso levantar duas outras questões. A primeira tange à organização dos sistemas escolares, os quais podem aumentar ou atenuar o impacto das desigualdades sociais sobre as desigualdades escolares. A segunda se refere aos impactos da escola, à influência dos diplomas para a mobilidade social. $\mathrm{O}$ artigo demonstra que, quanto mais determinante for o papel dos diplomas, mais marcadas serão as desigualdades escolares e mais rígida será a reprodução das desigualdades sociais. Finalmente, a função atribuída à escola pe-

1 Tradução de Patrícia C.R. Reuillard (UFRGS).

2 Artigo publicado originalmente em francês na revista Sociologie 2010/2 (vol.1), disponível em : < http://www.cairn.info/resume.php?ID_ARTICLE=SOCIO_002_0177>.

* Professor de sociologia na Université de Bordeaux 2, pesquisador do Laboratoire d'Analyse des Problèmes Sociaux et de l'Action collective (LAPSAC) e Diretor de estudos na École des hautes études en sciences sociales (EHESS) / Centre d'Analyse et d'Intervention Sociologiques (CADIS) - França. E-mail: francois.dubet@u-bordeaux2.fr

** Professora de sociologia no Institut d'Etudes Politiques de Paris / Observatoire sociologique du changement (OSC) - França. E-mail : marie.duru-bellat@wanadoo.fr *** Coordenador de estudos (Ingénieur d'études) do Laboratoire d'Analyse des Problèmes Sociaux et de l'Action collective (LAPSAC), Université de Bordeaux 2 - França. E-mail: antoine. veretout@u-bordeaux2.fr 
las diversas sociedades determinará a amplitude da reprodução social. Contudo, essa análise foi realizada a partir de uma amostra de países, logo a realização de estudos qualitativos complementares seria muito útil para melhor compreender como ocorre a reprodução social.

Palavras-chave: desigualdades escolares, desigualdades sociais, sistema educativo, reprodução social, diplomas, comparação internacional.

\section{Upstream and Downstream School Inequalities. School Organization and Diplomas Influence}

\section{Abstract}

School reproduces social inequalities everywhere as it is more favorable to already advantaged pupils. This is, however, a too general "law" for explaining the large variations revealed by international comparisons in the amplitude of this reproduction. Relying upon these studies, this paper shows first that these variations cannot be explained directly by the amplitude of social inequalities. In order to explain them, two other factors must be raised. The first one concerns the organization of the school systems, which may either widen or mitigate the impact of pupils' social background on their academic achievement. The second one concerns the influence of diplomas on access to various social positions. The paper shows that the more diplomas play a deciding role, the more pronounced are school inequalities and the more acute is the reproduction of social inequalities. Finally, it is not only what is produced in school and through its operation that determines the amplitude of the reproduction, but the own role attributed to school by the various societies. This study achieved on a sample of countries stands at an aggregate level, and some qualitative complementary studies would be very useful for better understand how social reproduction operates.

Keywords: school inequalities, social inequalities, educational system, social reproduction, diplomas, international comparison 


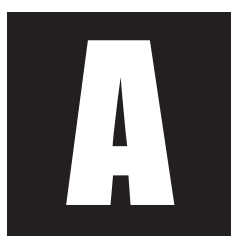

"função" de reprodução da escola é uma invariante das sociedades modernas, que precisam encontrar nos veredictos escolares, ratificando as competências e o mérito das pessoas, a justificativa das hierarquias sociais produzidas pelas desigualdades escolares. Consequentemente, a reprodução passaria, primeiro, pela transformação das desigualdades sociais em desigualdades escolares de mesma extensão e, depois, das desigualdades escolares em desigualdades sociais em um circuito idêntico de repetição.

Essa tese não é apenas a-histórica, como foi criticada (Petitat, 1982), ela é também muito ligada à concepção francesa do papel da escola, conforme revelam as teses de Bourdieu e Passeron (1964, 1970), feitas em um período com raros estudos comparativos. Nos últimos vinte anos, eles se multiplicaram e, embora confirmem que, em todos os países ricos, as desigualdades sociais "determinam" as desigualdades escolares, mostram também que essa determinação tem uma amplitude muito variável conforme os países. Em outras palavras, as relações entre as desigualdades escolares e as desigualdades sociais não são perfeitamente uniformes. Isso leva a se questionar se a escola exerce por toda parte o mesmo papel, do mesmo modo e com a mesma extensão no mecanismo da reprodução social - que é efetiva em todos os países, como mostram os avanços da sociologia comparada da mobilidade social (Breen et al., 2004).

As variações observadas entre os diversos países podem ser explicadas de duas maneiras. Pode-se, primeiramente, questionar o papel exercido pela própria organização dos sistemas escolares na transformação, mais ou menos fiel, das desigualdades sociais em desigualdades escolares. Mas também se pode deslocar o questionamento para o que acontece depois da escola, para o modo como as sociedades utilizam e valorizam os títulos escolares. As teses da reprodução postulam uma relação de continuidade entre o que antecede a escola, as desigualdades sociais, e as desigualdades escolares, mas também entre as desigualdades escolares e o que sucede à 
escola, as desigualdades das posições sociais ocupadas pelos alunos ${ }^{3}$. No entanto, essa cadeia está longe de se revelar automática quando se compara uma amostra de países relativamente comparáveis a fim de saber como os diplomas determinam as posições sociais. Pode-se levantar a seguinte hipótese: quando um país considera que os diplomas devem determinar estritamente as posições sociais, não somente as desigualdades escolares desempenham um papel social considerável no futuro dos indivíduos, mas também os pais vão fazer tudo para aumentar a vantagem escolar relativa de seus filhos, visto que seu futuro depende totalmente disso. Em contrapartida, as mesmas desigualdades escolares exercerão um papel bem diferente em um país que atribui menos peso aos diplomas e desenvolve outros sistemas de qualificação profissional e/ou dá acesso ao emprego. Para compreender o papel da escola na produção e na reprodução das desigualdades sociais, não se devem analisar apenas as consequências escolares das desigualdades sociais, mas também os efeitos sociais das desigualdades escolares. É no jogo desses dois mecanismos que se ancoram as diferenças entre os países: o funcionamento da escola e a influência dos diplomas sobre o acesso às posições sociais pesam tanto quanto as desigualdades sociais que antecedem a escola na formação das desigualdades escolares e nas consequências sociais dessas desigualdades.

\section{Fontes e métodos ${ }^{4}$}

A comparação entre as sociedades e os sistemas escolares pode seguir dois caminhos opostos: coletar uma grande quantidade de dados e

3 É o conjunto dessa cadeia causal que deveria ser testado; assim, que pesquisadores como R. Moore (1996) contestaram o modelo da reprodução, salientando como uma anomalia o fato de que, de um lado, as meninas, sexo "dominado", têm mais êxito na escola e que, por outro lado, esse êxito escolar não as leva a ocupar posteriormente uma posição dominante.

4 Esta pesquisa recebeu o financiamento do ANR (Agence Nationale de La Recherche) para o período de 2007-2010. 
fazer uma análise qualitativa, nesse caso necessariamente reduzida a um pequeno número de países ${ }^{5}$, ou se apoiar em bases de dados internacionais, o que condena certamente a trabalhar em um nível muito global, mas permite examinar um grande número de países. Esse tipo de raciocínio e de metodologia se assemelha ao benchmarking, à comparação ponderada entre os indicadores construídos pelas grandes pesquisas e organismos internacionais. É um método familiar hoje em dia, principalmente para os economistas, que se interrogam sobre a eficiência dos sistemas e das legislações sociais, dos modos de organização e dos investimentos públicos sobre a produtividade, o emprego, a inovação, etc.

O fato de recorrer a esse modelo de análise responde a fortes regras de prudência. Independentemente de sua qualidade e precisão, os indicadores com que trabalhamos são apenas indicadores. Não se deve ignorar que privilegiam certas dimensões da vida social e ignoram outras igualmente importantes. Além disso, contêm erros de medida maiores ou menores. Portanto, eles não são a "realidade" das sociedades e dos sistemas escolares. Ora, é fácil se equivocar, nesse caso, como mostram muitas pesquisas que ignoram tudo o que as enquetes não medem e constroem, assim, puras ficções estatísticas tidas por conjuntos sociais reais. É particularmente muito enganador examinar uma por uma das séries de indicadores isolados. Mesmo que sempre se consiga estabelecer uma correlação estatisticamente significativa entre este e aquele indicador, principalmente porque, em geral, se analisam grandes efetivos, fazer afirmações de natureza causal seria ainda mais imprudente porque um indicador correlato a outro frequentemente só "funciona" quando associado a um conjunto de fatores mais ou menos "ocultos", ou, pelo menos, ligados a

5 Ver, por exemplo, as instigantes análises de M. Osborn, P. Broadfoot, E. McNess, C. Planel, B. Ravn \& P. Triggs (2003). 
um e/ou outro dos indicadores ${ }^{6}$. Como a sociedade não é uma soma de indicadores independentes e adicionáveis, convém considerar a partir de países precisos, apreendidos globalmente e em sua história.

Por outro lado, todo trabalho de comparação internacional baseado sobre correlações não deve esquecer que muitas correlações detectadas são significativas apenas devido a um ou dois países atípicos; frequentemente, basta "mexer" na amostra, acrescentando ou cortando dois ou três casos, para que a natureza das correlações se transforme completamente. Por conseguinte, a argumentação que propomos aqui deve ser considerada indicativa, talvez até mesmo instigante, mas é acima de tudo um instrumento de análise que comporta necessariamente uma parcela de abstração e alguns pressupostos normativos implícitos relativos à própria natureza dos indicadores escolhidos. Enfim, uma fonte inevitável de dificuldades, que demanda prudência, situa-se nos próprios indicadores disponíveis. Baseamo-nos nas grandes bases de dados que, mesmo emanando dos organismos mais respeitáveis, apresentam algumas lacunas: dados ausentes para certos países, datas variáveis de coleta das informações ${ }^{7} .$. Elas impõem uma escolha de países relativamente próximos uns dos outros em termos de PIB por habitante e de índices de escolarização para que as comparações façam sentido, o que condicionará os resultados.

6 Tomando um exemplo fictício, observando uma correlação entre o nível dos conhecimentos dos alunos no PISA e o nível de formação dos professores, é possível que essa correlação, longe de indicar uma influência da segunda variável sobre a primeira, traduza a influência da variável "oculta" riqueza do país, relacionada ao mesmo tempo ao nível dos alunos e à possibilidade de formar os professores para um alto nível.

7 Os indicadores que caracterizam os sistemas educativos levam em conta os desempenhos e as desigualdades escolares, os índices de escolarização, o rendimento dos diplomas, o financiamento da educação, etc. Esses dados, na maioria provenientes da OCDE, são relativos ao ano de 2005 e vêm de "Regards sur l'éducation 2007". 
As comparações específicas entre os sistemas educativos se multiplicaram com a realização das grandes enquetes internacionais sobre os conhecimentos adquiridos dos alunos e deram origem a algumas tipologias, que se baseiam em uma seleção de parâmetros objetivos como os índices de escolarização nos diversos níveis dos sistemas educativos. Principalmente a partir das enquetes $\mathrm{Pisa}^{8}$, elas consideram os desempenhos dos alunos e sua dispersão; por vezes, também incluem a rentabilidade dos diplomas ${ }^{9}$. Com muita frequência, essas enquetes cruzam dados com os tipos de organização dos sistemas escolares, seu grau de centralização, as formas de seleção e a hierarquia dos estabelecimentos (Green et al., 2006; Mons, 2007).

No que diz respeito à apreensão das desigualdades escolares, os dados disponíveis são numerosos. Baseiam-se na disparidade dos conhecimentos adquiridos entre alunos - variância dos desempenhos principalmente no Pisa -, ou nas desigualdades sociais de desempenhos avaliados pelo peso da origem social dos alunos na explicação estatística de seus desempenhos. Na pesquisa aqui apresentada, para apreender as desigualdades de conhecimentos adquiridos no nível dos países, utilizamos um indicador de dispersão construído pela média dos desvios padrão de distribuição dos escores, das respostas às diferentes enquetes e conforme as disciplinas. Esse indicador se revela fortemente correlato $(R=0,4111$;

8 Pisa (Programme for International Student Assessment). Trata-se de um programa internacional de avaliação dos conhecimentos adquiridos pelos jovens de 15 anos e que são supostamente úteis para a vida diária ("life-skills"). A primeira enquete foi em 2000 e abrangeu 43 países, focalizando o domínio da língua materna. Uma segunda enquete foi feita em 2003 e focou a matemática; uma terceira ocorreu em 2006, focalizando as ciências. Uma nova enquete começou em 2009 e abrange 62 países.

9 Ver os numerosos relatórios de OCDE publicados a partir dos dados Pisa desde 2000 (principalmente OCDE, Literacy Skills for the World of Tomorrow, Paris, OCDE, 2003). 
Sig. $=0,033)$ da parcela de variância dos desempenhos explicada pela origem social dos alunos ${ }^{10}$, o que permitiu a construção de uma variável global de "desigualdade escolar".

\section{Desigualdades escolares variáveis: contextos globais e organizações escolares}

Dentro de um conjunto de países relativamente comparáveis, as sociedades menos igualitárias teriam os sistemas escolares menos igualitários? Para responder a essa pergunta, cruzamos as desigualdades sociais medidas sobre as variações de renda ${ }^{11}$ e as desigualdades escolares avaliadas pelos dados Pisa. Na verdade, no gráfico seguinte, o valor baixo e não significativo da correlação $(R=-0,059)$ mostra claramente a ausência de relação estável entre as desigualdades de renda entre adultos e as desigualdades escolares dos alunos da faixa de 15 anos.

$10 \mathrm{Na}$ literatura especializada sobre o Pisa, o fato de este indicador estar ligado à amplitude da dispersão dos desempenhos leva a utilizar um outro indicador de desigualdade social, o "gradiente socioeconômico", isto é, a mudança de desempenho acarretada pela mudança de uma unidade do índice que apreende globalmente o meio social do aluno (ESCS). A classificação dos países pode ser ligeiramente diferente: por exemplo, os países da Europa do Sul revelamse mais desiguais a partir do indicador "porcentagem dos escores explicada pelo meio social de origem" do que a partir do gradiente, porque, se o meio social explica bem uma parte significativa da variância dos escores, esta não é muito importante em relação aos outros países. É difícil decidir o valor respectivo desses 2 indicadores, mas uma coisa é certa, as classificações dos países por essa medida devem sempre ser consideradas como indicativas.

11 As desigualdades de renda (entre adultos) não recobrem evidentemente as desigualdades sociais em sua globalidade, mas apresentam a vantagem de serem comparadas com mais facilidade, de um país a outro, do que as desigualdades de status profissional. 
Gráfico 1. Desigualdades escolares e desigualdades sociais (de renda)*

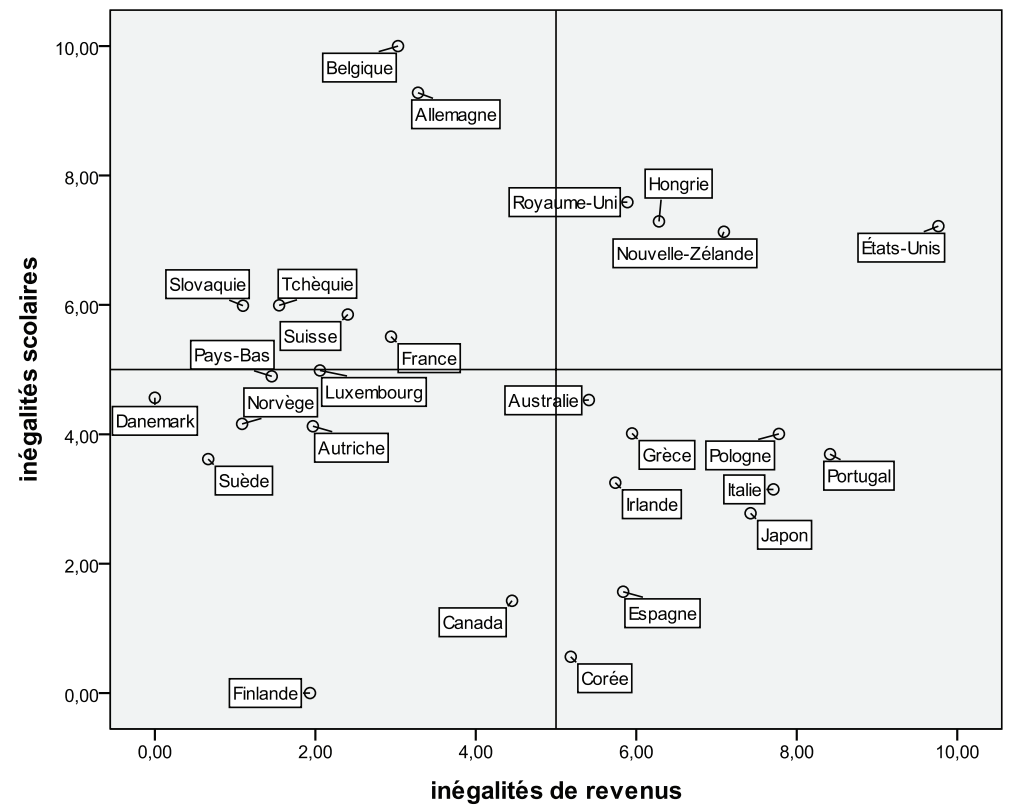

Nota de leitura: o gráfico classifica os países de acordo com o valor das desigualdades de renda (entre os adultos, a partir do indicador Gini disponível nos bancos de dados internacionais) e, ao mesmo tempo, com o valor do indicador de desigualdades escolares, que agrega o indicador de desigualdades dos conhecimentos escolares e o indicador de desigualdades sociais quanto a esses conhecimentos (dados Pisa). Em todos os gráficos, a classificação é realizada a partir dos valores normalizados das variáveis. Trata-se, portanto, de uma classificação e não de uma medida absoluta (por exemplo, as desigualdades de renda não são 8 vezes maiores em Portugal do que na Suécia).

* NT1 : Países indicados no gráfico 1: Alemanha, Austrália, Áustria, Bélgica, Canadá, Coreia, Dinamarca, Eslováquia, Espanha, Estados Unidos, Finlândia, França, Grécia, Hungria, Irlanda, Itália, Japão, Luxemburgo, Noruega, Nova Zelândia, Países-Baixos, Polônia, Portugal, ReinoUnido, República Tcheca, Suécia, Suíça. 
Certos países se caracterizam simultaneamente por grandes desigualdades de renda e grandes desigualdades escolares (quadrante superior/direito): é principalmente o caso dos Estados Unidos. Outros se encontram na situação inversa, combinando pequenas desigualdades escolares e sociais (quadrante inferior/esquerda), como essencialmente os países escandinavos. Esses dois exemplos paradigmáticos estão de acordo com o modelo simples da reprodução, já que as desigualdades escolares têm uma amplitude comparável às desigualdades sociais. Porém outros países apresentam situações em princípio menos esperadas. Em um caso, as desigualdades escolares são pequenas, ao passo que as desigualdades de renda são bem mais marcadas: como o quadrante inferior/direito do gráfico, onde se encontram a Itália, o Japão e Portugal... No outro caso, ao contrário, as desigualdades escolares são bem grandes em um contexto de desigualdades de renda relativamente moderadas: o quadrante superior/esquerdo, onde se encontram a França e alguns de seus vizinhos.

Esse resultado é suficientemente contra-intuitivo para que seu alcance seja ressaltado. Ainda que todas as pesquisas sociológicas mostrem que as desigualdades sociais entre os adultos "determinam" as desigualdades dos conhecimentos entre os alunos, a amplitude dessa determinação varia sensivelmente de um país a outro. Evidentemente, e uma grande quantidade de trabalhos de sociologia da educação o atesta, a desigualdade entre as famílias afeta os desempenhos dos alunos e produz mais ou menos desigualdades de conhecimentos entre eles. Todavia, o fato de que a escola não transforme as desigualdades sociais em desigualdades escolares com uma amplitude constante em todos os países significa que ela exerce um papel específico, já que pode acentuar ou, ao contrário, atenuar a amplitude dos efeitos das desigualdades sociais sobre as desigualdades escolares ${ }^{12}$.

12 Essa "ação" da escola pode evidentemente passar por muitos caminhos, que não poderíamos explorar todos aqui; dentre os não explorados, estariam evidentemente os estilos pedagógicos implantados nas classes, ou o papel mais ou menos importante atribuído aos estabelecimentos ou às famílias. 


\section{Níveis de escolarização e desigualdades escolares}

Poderíamos levantar, em princípio, esta hipótese: quanto mais alunos e por mais tempo os sistemas escolarizam, mais igualitários eles são. Esse foi um dos argumentos maiores das políticas de massificação e de democratização escolares. Na realidade, e o gráfico seguinte demonstra isto, não há correlação entre essas duas dimensões, não há relação estável entre a "integração escolar", medida pelo nível da escolarização e o nível dos conhecimentos ${ }^{13}$ e o das desigualdades escolares.

13 Hierarquizamos os países a partir de um indicador de integração escolar construído pela combinação da porcentagem de adultos que concluem um segundo ciclo secundário longo e o escore de desempenho alcançado nas enquetes Pisa. Assim, o sistema escolar com o maior nível de integração escolariza uma porcentagem importante de alunos até o fim de um segundo ciclo longo; por outro lado, leva os alunos de 15 anos a um escore médio de aquisição elevado. 
Gráfico 2. Integração escolar e desigualdades escolares*

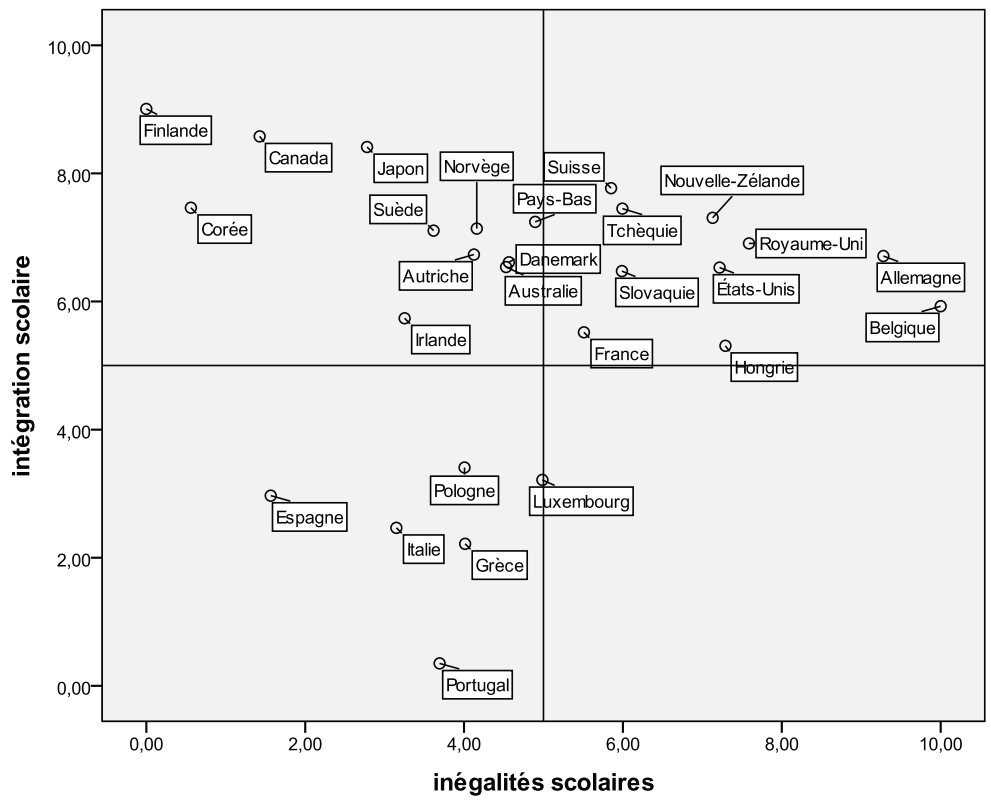

Nota de leitura: o gráfico classifica os países ao mesmo tempo em função da extensão das desigualdades escolares, desigualdades de conhecimentos e desigualdades sociais entre alunos e em função do nível de integração escolar (escolarização em segundo ciclo e nível médio dos conhecimentos).

* NT2: Países indicados no gráfico 2: Alemanha, Austrália, Áustria, Bélgica, Canadá, Coreia, Dinamarca, Eslováquia, Espanha, Estados Unidos, Finlândia, França, Grécia, Hungria, Irlanda, Itália, Japão, Luxemburgo, Noruega, Nova Zelândia, Países-Baixos, Polônia, Portugal, ReinoUnido, República Tcheca, Suécia, Suíça. 
Nos países "integradores", que escolarizam por muito tempo os alunos e lhes permitem alcançar um bom nível, pode-se detectar uma leve relação com a extensão das desigualdades: quanto mais o sistema escolariza e forma, maior a tendência a uma moderação das desigualdades. Mas se deve reconhecer que essa relação é pequena e que não possibilita enunciar nenhuma lei geral, segundo a qual bastaria aumentar o número de anos de estudos para reduzir automaticamente as desigualdades escolares. Todo um grupo de países tem níveis de integração escolares muito próximos e desigualdades escolares bastante contrastantes. Há também um pequeno grupo de países - Espanha, Portugal, Grécia, Itália e Polônia - com desempenhos e índice de escolarização baixo e desigualdades escolares também relativamente pequenas. Outros países, porém, do Reino-Unido à Hungria, passando pela Bélgica e pela Alemanha, têm uma integração escolar relativamente alta associada a grandes desigualdades escolares.

Se é suficiente abrir a escola para que o nível aumente globalmente, como sugere a forte correlação positiva $(R=0,514$; Sig $=0,006)$ entre índices de escolarização e desempenhos dos alunos ${ }^{14}$, certamente não basta para reduzir as desigualdades escolares, quer sejam medidas em termos de variações de desempenhos dos alunos ou em termos de influência da origem social sobre esses desempenhos. Observemos que a França se encontra nessa situação, como sabem muitos especialistas quando salientam que, neste país, a escola é eficaz apenas para uma parte dos alunos. C. Batelot e R. Establet (2009) ressaltam que os alunos franceses com 15 anos e sem atraso escolar têm conhecimentos superiores ao nível médio dos alunos dos países mais bem classificados nas enquetes Pisa, enquanto os alunos atrasados puxam para baixo os desempenhos franceses.

14 Trata-se apenas de uma correlação, indicando que são os mesmos países que desenvolvem a escolarização e têm alunos com nível elevado; qualquer conclusão extraída de uma correlação só pode ser hipotética... 
Esse gráfico leva, portanto, a distinguir quatro conjuntos de países: - O primeiro grupo associa um alto nível de integração a pequenas desigualdades escolares; compreende o Canadá, a Coreia, a Finlândia e o Japão.

- O segundo grupo se caracteriza por um alto nível de integração associado a desigualdades médias: Austrália, Áustria, Dinamarca, Noruega, Irlanda, Países-Baixos, Suécia, Suíça, República Tcheca, Eslováquia e França.

- O terceiro grupo combina uma escolarização e desempenhos igualmente altos e, portanto, um forte nível de integração, com grandes desigualdades: Alemanha, Bélgica, Hungria, Reino-Unido, Estados Unidos e Nova Zelândia.

- O último conjunto é caracterizado por uma escolarização e desempenhos fracos e, consequentemente, por um nível baixo de integração. Mas esse nível é associado a desigualdades médias ou pequenas na Itália, em Luxemburgo, na Polônia, em Portugal e na Grécia.

Essa tipologia empírica, cujas fronteiras podem ser questionadas, demonstra que o índice de escolarização não é, em si, um fator de redução das desigualdades escolares. Embora seja geralmente associado à elevação do nível médio dos alunos, ele não basta nem para reduzir as variações de desempenhos entre os alunos, nem para limitar a influência do meio social sobre seus conhecimentos. Estender a escolarização não é, por si só, uma garantia de justiça escolar. Na verdade, tudo depende da maneira como a escola se organiza e do que se faz nela.

\section{Os efeitos de organização}

Nossos dados confirmam, essencialmente, o papel da organização do sistema escolar na produção do nível e das desigualdades escolares, já salientado por toda uma literatura sociológica que, na esfera das enquetes 
Pisa, compara os "desempenhos" dos sistemas educativos com algumas de suas características organizacionais (Duru-Bellat, Mons, Suchat, 2004; Green, 2008; Mons, 2007; Perry, 2008).

Espera-se, primeiramente, que a duração do tronco comum seja um parâmetro pertinente por indicar o período em que todos os alunos são escolarizados juntos. Quanto mais longo for o tronco comum unificado, que corresponde ao collège unique* francês, menores serão as desigualdades escolares. A correlação é muito significativa $(R=-0,540 ;$ Sig =0,004).

\footnotetext{
* Tipo de estabelecimento escolar situado entre a escola primária e o ensino médio, implantado na França em 1975. Em 4 anos de estudos, acolhe todos os alunos do primeiro ciclo do secundário e oferece uma formação idêntica, sem habilitações. O objetivo do collège unique é ampliar e democratizar o acesso à educação. (N. de trad.)
} 
Gráfico 3. Duração do tronco comum e desigualdades escolares*

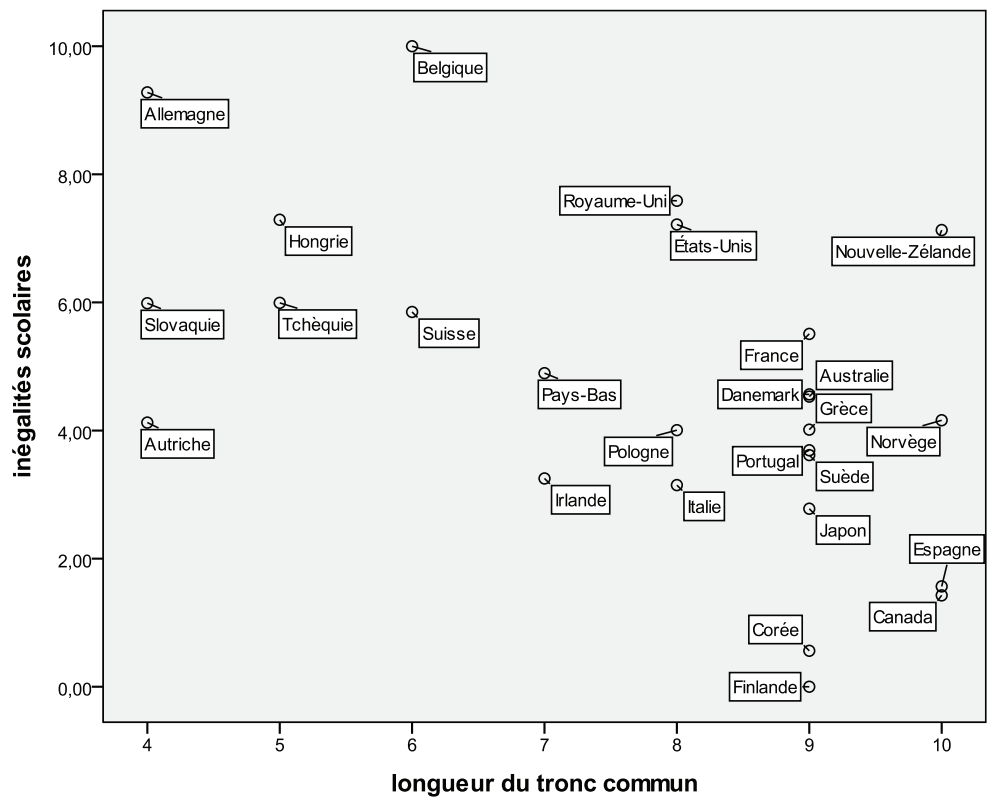

Nota de leitura: o gráfico classifica os países em função da duração do tronco comum (de 4 a 10 anos) e, ao mesmo tempo, em função da extensão das desigualdades escolares (desigualdades de conhecimentos e desigualdades sociais).

* NT 3: Países indicados no gráfico 3: Alemanha, Austrália, Áustria, Bélgica, Canadá, Coreia, Dinamarca, Eslováquia, Espanha, Estados Unidos, Finlândia, França, Grécia, Hungria, Irlanda, Itália, Japão, Noruega, Nova Zelândia, Países-Baixos, Polônia, Portugal, Reino-Unido, República Tcheca, Suécia, Suíça. 
De modo geral, os países que têm os troncos comuns mais curtos (até 6 anos) são mais desiguais no quesito escola do que os países cujo tronco comum é mais longo, 9,33 em média. Nenhum dos países com habilitações na faixa de 14 anos pertence ao grupo dos sistemas escolares mais igualitários. Em contrapartida, no grupo dos países com longos troncos comuns, a dispersão das desigualdades é extremamente pronunciada: as desigualdades são muito pequenas na Finlândia, ao passo que são bem mais elevadas na França. A duração do tronco comum não basta para caracterizar os sistemas escolares, é preciso considerar então o modo de organização pedagógica da escola "média", isto é, o nível secundário inferior. Nesse caso, pode-se empregar a tipologia de Mons (2007), construída essencialmente sobre a organização desse nível de ensino, que corresponde ao primeiro ciclo do secundário francês, o collège ${ }^{15}$.

A principal clivagem opõe os países onde prevalece o chamado sistema de separação, com uma diversificação/seleção precoce em habilitações (tracking), que caracteriza um "modelo germânico", a todos os países, majoritários, que adotaram um ciclo comum para o "secundário inferior", como o collège na França. Em todos os casos, os países que escolheram a seleção precoce dos alunos têm baixos índices de escolarização comum associados a desigualdades elevadas - Alemanha, Bélgica ou Hungria - e a desigualdades moderadas, como os Países-Baixos, a Suíça e a República Tcheca.

Os países que propõem uma escolarização comum mais longa optam por modalidades diferentes de tratamento das dificuldades dos alunos. Nesse grupo, podem ser assim distinguidas três fórmulas de organização do ciclo comum (Mons, 2007).

15 Essa tipologia é, evidentemente, discutível, mas tem a vantagem de não se deter em uma análise puramente formal dos sistemas (já que as variações entre a norma e o funcionamento efetivo foram levadas em conta). As denominações escolhidas para os diferentes tipos não têm, é claro, conotação normativa. 
1) O modelo da integração individualizada, que oferece recursos de apoio individualizado não somente para os alunos fracos, e onde a reprovação é impossível, como tampouco a organização em classes de nível. Todos os países da Europa do Norte o empregam.

2) O modelo chamado de integração à la carte, onde existe um tronco comum, "relativamente comum", esclarece Mons, mas com a possibilidade de formar grupos de níveis e uma gestão menos individualizada das dificuldades. Encontram-se nesse grupo a Austrália, o Canadá, a Nova Zelândia, os Estado Unidos...

3) Enfim, o modelo chamado de integração uniforme gere as dificuldades dos alunos frente a um tronco comum longo por meio da reprovação, às vezes, por classes de nível e, até mesmo, por saídas do sistema sem qualificação. Aqui se agrupam países como a Itália, a França ${ }^{16}$ e Portugal.

Todos os países que escolheram a integração individualizada apresentam um alto nível de escolarização, mas também pequenas desigualdades, como a Finlândia e o Japão, ou moderadas, como a Dinamarca. Todos os países que escolheram a integração à la carte têm um alto nível de escolarização associado a desigualdades variáveis: moderadas na Austrália, fortes no Reino-Unido e fracas no Canadá. Os países que optaram pela integração homogênea são caracterizados com muito mais frequência por um nível baixo de escolarização associado a desigualdades médias (Grécia), ou fracas (Espanha). A única conclusão que se pode avançar com mais firmeza diz respeito aos efeitos igualitaristas da integração individualizada, na qual as classes são heterogêneas e os professores adaptam seu trabalho às capacidades e aos ritmos singulares dos alunos.

16 Lembremos que a França se distingue por um nível particularmente alto de índices de reprovação: com 15 anos, cerca de um terço dos alunos já foi reprovado; com 18 anos, cerca da metade. 
Segregação escolar e desigualdades

As desigualdades entre os alunos podem depender do nível de segregação social e escolar dos estabelecimentos. A maneira como se agrupam os alunos pode desempenhar um papel decisivo em suas aquisições e na formação das desigualdades. Reunir os melhores de um lado e os mais fracos do outro pode aumentar as distâncias e baixar o nível médio, pois, nesse caso, os mais fracos progridem particularmente pouco (Duru-Bellat, Mingat, 1997). Essas maneiras mais ou menos segregativas de agrupar os alunos dependem das políticas escolares e, ao mesmo tempo, do nível de segregação espacial das desigualdades sociais: quando as diversas classes sociais são muito separadas e concentradas na cidade, os diversos públicos escolares ficam também muito segregados. Retomamos aqui duas variáveis sintéticas construídas por Demeuse e Baye (2008) sobre um subconjunto infelizmente reduzido de países ${ }^{17}$. Uma delas mede a segregação dos públicos escolares aos 15 anos sob múltiplos ângulos: desigualdades escolares ou sociais entre alunos, origem linguística, naturalidade dos pais, etc. A outra mede o caráter segregativo das próprias estruturas escolares; essa variável é construída agregando os modos de agrupamento dos alunos, os recursos privados, a escolha da escola deixada à iniciativa dos pais, o índice de reprovação... Essas duas variáveis globais são evidentemente correlatas, mas sua relação não é tão forte quanto se poderia pensar. Sem surpresa, certos países, principalmente os da Europa do Norte, apresentam escores baixos de segregação dos públicos e, simultaneamente, estruturas pouco segregativas, ao passo que o inverso é observado em países como a Alemanha, a Bélgica e os PaísesBaixos, onde os públicos são separados e as estruturas são segregativas.

17 A França, em particular, não forneceu dados por estabelecimento. 
Mas também existem casos menos nítidos que deveriam ser explorados mais qualitativamente; por exemplo, a Itália e, em menor grau, a Grécia, têm estruturas escolares pouco segregativas, mas um nível de segregação bastante elevado entre os estabelecimentos.

A segregação social e escolar entre os estabelecimentos que prevalece nos países é sempre associada a grandes desigualdades escolares. Há uma correlação significativa entre a amplitude das desigualdades escolares e o grau de segregação entre os estabelecimentos $(R=0,489$; Sig $=0,025)$ e, de maneira ainda mais marcada, com o caráter segregativo das estruturas escolares ( $R=0,718$; Sig $=0,000)$. Desse ponto de vista, a questão levantada pelo caráter misto dos estabelecimentos não é, pois, uma quimera; isso é ainda mais verdadeiro no caso das estruturas e práticas escolares segregativas, fortemente associadas à amplitude das desigualdades.

O grau desigual de segregação dos alunos mostra-se, então, como um importante parâmetro de diferenciação dos sistemas educativos sob o ângulo dos conhecimentos escolares e das desigualdades sociais aferentes. Aparentemente, encontra-se no nível dos países o tipo de resultados evidenciado no nível das classes, ou seja, classes de nível, portanto segregadas, acentuam as distâncias entre os alunos. Isso poderia levar, mas é menos sistemático, a desempenhos médios inferiores, visto que os alunos fracos agrupados entre si perdem bem mais do que os mais fortes em comparação com uma situação de heterogeneidade. Contudo, a segregação dos públicos entre estabelecimentos seria o parâmetro mais claramente associado à formação das desigualdades entre os alunos.

A relação entre a segregação dos públicos escolares e a amplitude das desigualdades entre os alunos também é mostrada em inúmeros trabalhos, mas a partir de variáveis diferentes. Assim, após ter introduzido um certo número de características estruturais dos sistemas educativos tais como o grau de padronização dos métodos, dos programas e dos con- 
troles, a presença do privado e a hierarquia entre habilitações organizada por um tracking precoce, Pfeffer (2007) concluiu que apenas este último parâmetro está associado a seu indicador de "mobilidade educativa". A educação se transmite mais sistematicamente de pai para filho quando a seleção precoce leva os itinerários dos alunos a divergir. De maneira convergente, ao término de sua análise comparativa de um grande número de sistemas escolares, Mons (2007) concluiu que os sistemas de seleção precoce são aqueles em que as desigualdades sociais são mais marcadas. Ela também mostra, enquanto destaca associações que parecem contudo menos sistemáticas, que há um vínculo entre fortes desigualdades escolares, setor privado forte e primazia da livre escolha das escolas pelas famílias. Nos sistemas mais igualitários, ao contrário, a escolha da escola é regulada, a descentralização é demarcada e a presença do privado é pequena. Sobre isso, Green (2008) insiste sobre o impacto da descentralização, que acarretaria desigualdades na qualidade da oferta escolar. Quer se trate da escolha da escola ou do peso do setor privado (ou então, mais isso é menos explorado, do funcionamento dos próprios estabelecimentos escolares), essas características dos sistemas afetariam a extensão das desigualdades entre os alunos de maneira indireta, acentuando a segregação dos estabelecimentos.

Em última análise, as diversas maneiras de organizar os estudos exercem um papel importante na amplitude das desigualdades entre alunos e, portanto, na construção dos mecanismos da reprodução social. É possível afirmar com bastante firmeza que os sistemas escolares mais igualitários implantam um tronco comum longo e homogêneo e são suficientemente centralizados para limitar a segregação entre as classes e os estabelecimentos. Mas isso não basta, pois, para serem igualitários, tais sistemas devem também individualizar as pedagogias e o trabalho dos alunos, de modo que a homogeneidade da formação não seja uma maneira de 
marginalizar aqueles que não se curvam à norma comum ${ }^{18}$. É necessário então que a escola associe virtudes relativamente contraditórias. Em todo caso, isso mostra que, ainda que a reprodução permaneça uma "lei" geral dos sistemas escolares, a amplitude dessa reprodução depende da maneira como a escola é organizada e como as aulas são dadas ${ }^{19}$.

\section{Os efeitos da escola: influência dos diplomas e reprodução social}

Para tentar compreender a diversidade das relações entre as desigualdades escolares e as desigualdades sociais, evidenciada no gráfico 1, não basta interrogar o funcionamento da escola, é preciso questionar o papel que exercem as desigualdades escolares certificadas pelos diplomas na formação das desigualdades sociais após a formação escolar. Foi o que fez, por exemplo, Louis Chauvel (1999) que, depois de constatar a ausência de correlação entre desigualdades escolares e desigualdades de renda em uma amostra de países europeus, concluiu que certas sociedades valorizam mais ou menos os diplomas e desenvolvem, mais ou menos também, sistemas de formação e/ou de qualificação alternativos à escola. As comparações internacionais focalizadas na estratificação social e em sua reprodução de uma geração à outra (Kerckhoff, 2000) mostram que, se em todos os países economicamente desenvolvidos os títulos escolares constituem o vetor privilegiado de transmissão das posições sociais entre pais e filhos, a intensidade e as modalidades precisas desse processo variam conforme os países. Isso se explica pelo fato de que a força do vín-

18 A tese de que as pedagogias individualizadas são um fator de desigualdade não parece tão sólida quanto acredita J.-P. Terrail (2005).

19 Se tentarmos estimar por meio de um modelo multivariado a amplitude das desigualdades escolares, levando em conta o nível de integração dos sistemas educativos e suas principais características, a parte de variância assim explicada não ultrapassa $40 \%$. 
culo entre os títulos escolares e as posições sociais ocupadas pelos alunos que saem do sistema de formação se revela muito desigual de um país a outro. As análises comparativas feitas por Shavit e Muller (1998) mostram isso claramente: os países diferem mais pelos modos de articulação entre as formações e os empregos, entre os diplomas e seu "rendimento" no mercado de trabalho do que pela amplitude das desigualdades diante do êxito escolar. Isso leva a se interessar muito particularmente pelo processo de inserção e pela maneira como os jovens "rentabilizam" seus diplomas.

Para fazê-lo, é necessário explorar o modo como o diploma se traduz em renda e em status social, o que chamaremos de influência do diploma. Com efeito, pode-se conceber que a variação da intensidade dos vínculos entre as desigualdades dos conhecimentos escolares e as desigualdades sociais "finais" se explica pelo fato de que, em certos países, os conhecimentos escolares têm pouco peso no futuro profissional das pessoas, enquanto são determinantes em outras sociedades. Em outras palavras, pode-se levantar a hipótese de que devemos nos deter nos modos de influência dos sistemas escolares sobre a sociedade, já que é o papel desempenhado pelas hierarquias escolares na formação das hierarquias sociais que exerce uma função essencial no processo de reprodução social.

Em uma análise mais completa, conviria incluir também as modalidades, igualmente variadas conforme os países, de mobilidade profissional durante a carreira, com ou sem formação contínua; em suma, o que alguns chamam de "regimes" de educação ao longo da vida (Buechtemann e Verdier, 1998). Essa foi uma das conclusões da pesquisa de Maurice, Sellier e Sylvestre (1982) sobre a Alemanha e a França: embora selecionados de modo mais prematuro e injusto pela escola, os operários alemães tinham carreiras mais favoráveis do que os operários franceses graças à qualidade de sua formação e a um sistema de mobilidade profissional mais aberto, porque menos apegado ao peso dos diplomas de 
base. Uma coisa é certa, a formação, inicial ou contínua, não é tudo: o papel da escola é demarcado pelas estruturas econômicas e as características do mercado de trabalho após a escolarização. Em um país como a França, convencido de que apenas as desigualdades sociais que afetam os percursos escolares dos alunos são determinantes, essa constatação deve ser vigorosamente salientada.

Entre a escola e a sociedade: a influência dos títulos escolares

O impacto da escola sobre a sociedade, principalmente suas desigualdades e sua reprodução, dependeria, na verdade, das relações entre os diplomas e os empregos. No caso em que a influência dos diplomas sobre as posições sociais é grande ou percebida como tal, já que os atores não ignoram absolutamente esse fenômeno, pode-se imaginar que se entregam a uma competição escolar intensa a fim de garantir a posição de seus filhos. Sabemos então que as categorias mais favorecidas têm todas as chances de ganhar esse jogo que favorece a reprodução social e esperamos encontrar uma correlação positiva entre a influência dos diplomas e a amplitude das desigualdades escolares.

No entanto, o saldo desse modo de funcionamento permanece incerto, e os efeitos da influência dos diplomas podem ser diferentes, até mesmo divergentes, no que diz respeito aos indivíduos - nível micro - e às sociedades - nível macro. No nível dos indivíduos, a forte influência dos diplomas é interessante para os mais titulados, mas penaliza os "vencidos" do sistema escolar. É difícil prever como vão se compor esses efeitos contraditórios no nível macrossocial, ou seja, como a reprodução acontece, e com que intensidade, em todos os casos em que a influência dos diplomas é mais moderada. Seria a sociedade menos injusta, já que a escola não detém o monopólio da seleção dos indivíduos, ou mais injusta, como desejaria a ideologia meritocrática que aceita apenas as desigualdades produzidas pelo 
diploma e rejeita como ilegítimas aquelas que passariam pelas redes ou por qualidades pouco escolares? Nesse caso, pode-se enfim supor que os mecanismos de reprodução social são ainda mais fortes porque a influência dos diplomas faz parte da legitimação das desigualdades sociais: estas são percebidas como justas, pois foi a escola que as produziu.

A variável "influência" é construída pela associação de duas variáveis: de um lado, a influência dos diplomas sobre o emprego (índice de emprego dos detentores de um diploma do ensino superior em relação àquele dos indivíduos com um diploma inferior ao ensino médio); de outro, a influência dos diplomas sobre os salários (salário médio dos diplomados do setor terciário em relação àquele dos indivíduos com um diploma inferior ao ensino médio ${ }^{20}$. Essa variável abarca, portanto, a amplitude das vantagens econômicas trazidas pelo diploma, mais precisamente por um diploma do ensino superior, que constitui o nível de estudos mais discriminante em nossa amostra de países relativamente ricos e escolarizados nesse nível. Quanto mais alto é o valor dessa variável, mais "rentáveis" são os diplomas em termos de inserção e/ou de salários no mercado de trabalho, e mais alta, então, é a influência dos diplomas.

20 Dados de 2002 (Regards sur l'éducation, OCDE, 2004). Para a Grécia, o Japão e a Eslováquia, a variável "influência" mede apenas o diferencial de índice de emprego. 
Gráfico 4. Impacto do diploma sobre os salários e desigualdades de renda*

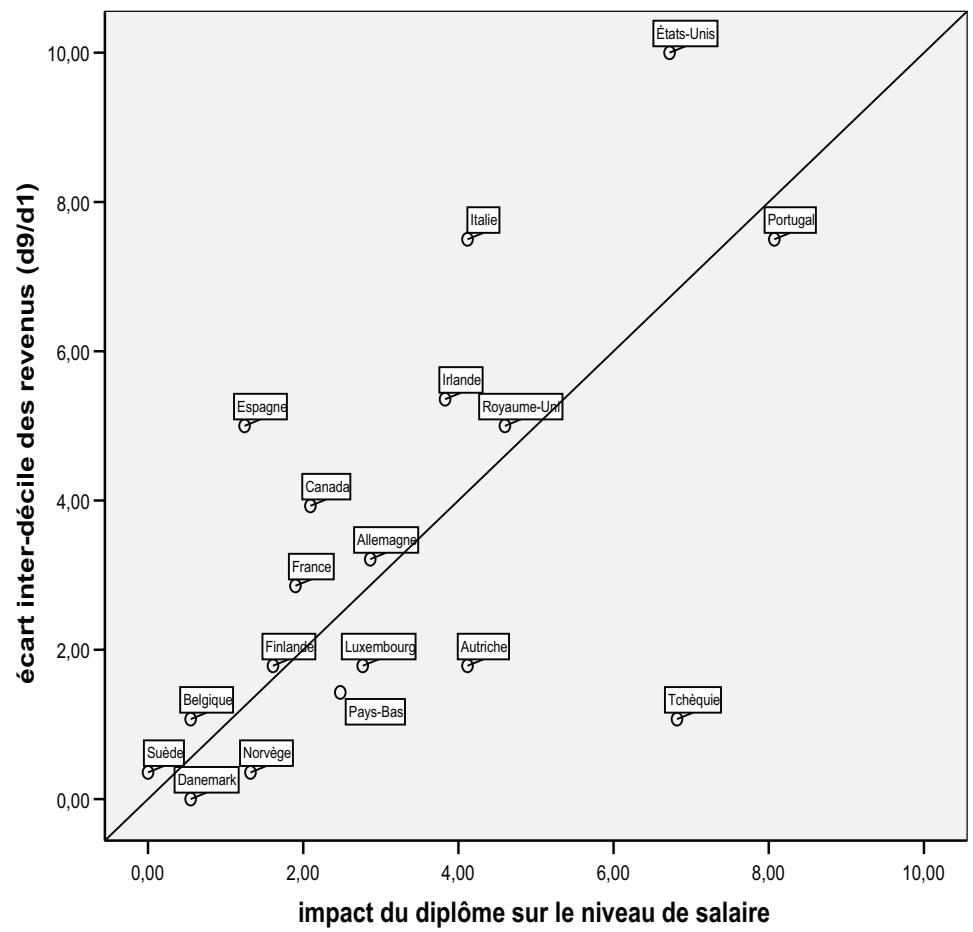

Eixo horizontal: impacto do diploma sobre o nível salarial / Eixo vertical: Intervalo interdecil de renda Nota de leitura: o gráfico classifica os países para os quais essas duas informações estão disponíveis de acordo com o valor do indicador de impacto do diploma sobre os salários e, ao mesmo tempo, com o indicador de desigualdades de renda.

* NT 4: Países indicados no gráfico 4: Alemanha, Áustria, Bélgica, Canadá, Dinamarca, Espanha, Estados Unidos, Finlândia, França, Irlanda, Itália, Luxemburgo, Noruega, Países-Baixos, Portugal, Reino-Unido, República Tcheca, Suécia. 
As sociedades onde os diplomas se revelam particularmente rentáveis tendem a apresentar grandes desigualdades salariais: o impacto dos diplomas sobre os salários é correlato à amplitude das desigualdades de renda, a relação é mais nítida e significativa $(R=0,647$; Sig $=0,004)$. De modo geral, quanto menos os diplomas determinam os salários, menores são as desigualdades de renda. Portanto, é provável que a influência dos diplomas seja um fator de aprofundamento das desigualdades salariais, mesmo que estas resultem de outros processos econômicos e sociais. Mas também é possível que a relação seja inversa: quando as desigualdades salariais são grandes criam-se critérios para distinguir os indivíduos, e o diploma se revela um critério objetivo e legítimo. Os diplomas passam então a ser mais valorizados ainda e é a amplitude das desigualdades salariais que, nesse caso, explica a intensidade da influência escolar.

Influência do diploma e desigualdades escolares

Como já sugerimos, pode-se levantar a hipótese de que uma relação estreita entre a formação e o emprego cristaliza as desigualdades que se formaram na escola. Quanto mais indispensáveis são os diplomas, mais interesse têm os atores, individualmente, de aumentar as distâncias escolares para fazer diferença. O jogo escolar seria mais descontraído se os diplomas fossem menos vitais. Efetivamente, observa-se, em média, uma correlação significativa entre a influência dos diplomas e as desigualdades escolares $(R=0,327$; Sig $=0,096)$ : quanto maior a influência dos diplomas, mais marcadas as desigualdades escolares. Nesse caso, pode-se imaginar que, quanto mais "rentáveis" os diplomas, até mesmo aparentemente indispensáveis, mais interesse têm os alunos e as famílias de endurecer a competição escolar a fim de garantir as vantagens diferenciais que fundamentam a utilidade dos diplomas. E quanto mais as famílias se envolvem nessa lógica, mais consolidam as desigualdades, já que os mais bem colocados farão 
tudo para manter sua posição escolar para reproduzir a posição social, e provavelmente terão êxito nisso exatamente devido às suas vantagens. Essa vertente da realidade é bastante conforme à tese da reprodução.

Gráfico 5. Influência dos diplomas e desigualdades escolares*

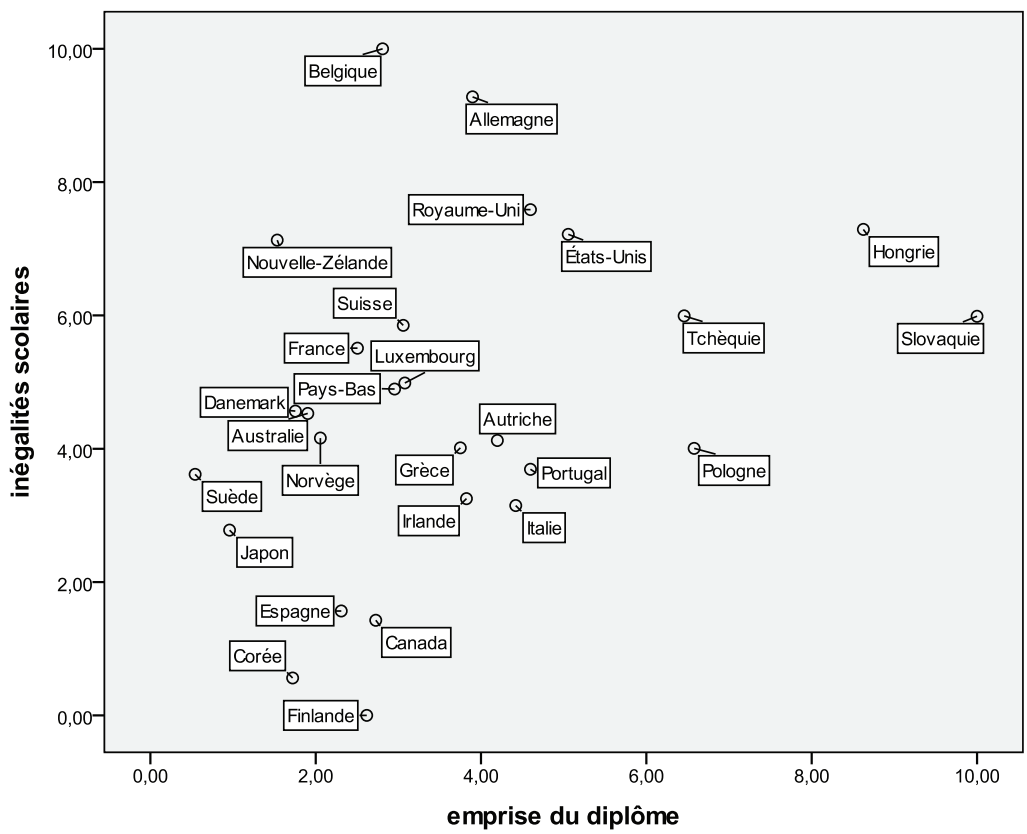

Nota de leitura: o gráfico classifica os países de acordo com o valor do indicador da influência dos diplomas e do indicador de desigualdades escolares.

* NT 5: Países indicados no gráfico 5: Alemanha, Austrália, Áustria, Bélgica, Canadá, Coreia, Dinamarca, Eslováquia, Espanha, Estados Unidos, Finlândia, França, Grécia, Hungria, Irlanda, Itália, Japão, Luxemburgo, Noruega, Nova Zelândia, Países-Baixos, Polônia, Portugal, ReinoUnido, República Tcheca, Suécia, Suíça. 
A correlação entre as desigualdades escolares e a influência dos diplomas lembra um dos paradoxos do modelo meritocrático que domina a maioria dos sistemas escolares e governa o papel que a sociedade lhes confia; quanto mais se acredita que a escola pode construir desigualdades justas, mais justo parece que estas tenham uma forte influência sobre o destino profissional dos indivíduos. Mas, com o tempo, quanto maiores são as desigualdades escolares e mais se reproduzem assim, mais isso contradiz o ideal meritocrático que suporia que a reprodução das desigualdades fosse a menor possível, já que deveria repousar, em princípio, em uma distribuição aleatória dos talentos e da vontade (Dubet, 2004).

Uma sociedade conforme ao modelo meritocrático conjugaria, de um lado, uma ausência de desigualdades sociais escolares e uma pura igualdade das chances - podendo cada criança mostrar seus méritos escolares independentemente de seu meio social - e, de outro, uma grande influência do diploma - sendo os méritos que ele ratifica recompensados de maneira justa no mercado de trabalho. O esquema clássico da análise da atribuição dos lugares nas sociedades modernas - o esquema origem-educaçãodestino - prevê que, no caso de uma sociedade puramente meritocrática, os "destinos", isto é, os lugares, supostamente decorrem estritamente da educação recebida (Goldthorpe, 1996). Haveria, portanto, uma relação forte entre educação e destinação, o que designamos aqui como uma forte influência. Ainda nessa sociedade meritocrática, não deveria haver nenhuma relação entre origem e educação, isto é, nenhum efeito maior da origem social sobre as desigualdades escolares nem, é claro, efeito preciso da origem sobre o destino. Ora, nenhum dos países estudados aqui corresponde a esse esquema teórico: em particular, os países cujas desigualdades escolares são pequenas são também aqueles em que a influência dos diplomas é pequena, e os países em que prevalecem fortes relações formaçãoemprego são também aqueles nos quais as desigualdades sociais diante da 
escola têm um papel importante. Essa constatação ${ }^{21}$ questiona fortemente a ideologia meritocrática para a qual as vantagens ligadas à educação (principalmente posição social e salário) são justas, visto que decorrem do mérito; considerando que grandes vantagens decorrentes da educação se conjugam com grandes desigualdades sociais de acesso à educação, tais vantagens constituem claramente uma fonte de injustiças.

As características dos sistemas educativos também podem ser associadas a níveis desiguais de influência dos diplomas. Gross (2003) revela que os países em que a influência é grande têm sistemas educativos mais centralizados e mais hierarquizados do que os outros, o que torna os diplomas mais legíveis aos olhos dos empregadores, contribuindo assim para seu "rendimento" potencial. Suas conclusões coincidem com as de Shavit e Muller (1998), que mostram que a influência dos diplomas é mais intensa quando os sistemas educativos apresentam um caráter estratificado, ou seja, quando comportam habilitações distintas e hierarquizadas. Nossos próprios dados confirmam essas análises. Observa-se, sobretudo, uma relação negativa significativa entre a variável influência e a duração do tronco comum ( $R=0,649$; Sig $=0,000)$, sendo a influência tanto mais forte quanto mais breve for o tronco e mais precoces as habilitações hierarquizadas. Observa-se também uma relação positiva significativa com a segregação dos públicos $(R=0,481$; Sig $=0,027)$ : a influência é mais forte quando os públicos escolares são segregados, o que frequentemente acompanha, aliás, um tronco comum breve e habilitações precoces. Há, portanto, uma relação entre a rigidez das relações entre formações e empregos. Os diplomas trazem mais vantagens porque são raros, como mostra a forte correlação negativa com a porcentagem de diplomados

21 Encontram-se resultados convergentes em um estudo europeu recente que concluiu que os países onde as desigualdades sociais diante da escola são mais reduzidas são também aqueles em que as vantagens ligadas à educação são mais limitadas. Cf. A. Baye, M. Demeuse, C. Monseur e C. Goffin (2006), Un ensemble d'indicateurs pour mesurer l'équité des 25 systèmes éducatifs de l'Union Européenne, Liège, Service de Pédagogie expérimentale. 
do setor terciário ( $R=0,656$; Sig $=0,000)$. Isso tende a validar a tese da "inflação escolar" que, a exemplo da inflação monetária, evidencia uma perda de valor dos diplomas associada à sua fortíssima difusão (DuruBellat, 2006). Enfim, existe uma correlação positiva muito marcada entre a influência dos diplomas e o desemprego dos jovens $(R=0,733$; Sig $=$ 0,000), o que confirma a ideia de que a influência dos diplomas é mais necessária quando o "racionamento" dos empregos é significativo; em um contexto de grande concorrência por empregos raros, o critério do diploma faz parte da organização da "fila de espera" dos jovens.

Essas diversas características das relações das sociedades e de seu sistema educativo se conjugam e se pode avaliar sua importância relativa em um modelo multivariado, comparando-as com a variável influência. Quando se leva em conta ao mesmo tempo as desigualdades sociais globais e as características escolares, nenhuma variável se distingue por um impacto significativo específico sobre a variável influência. Em particular, as diferentes características do sistema educativo não atuam significativamente sobre a força das relações formação-emprego. Em um modelo mais econômico (cf. quadro abaixo), somente duas variáveis têm um impacto significativo e marcado: o dinamismo do mercado de trabalho ${ }^{22} \mathrm{e}$ a amplitude das desigualdades escolares. Sozinhas, elas explicam 33,2\% da variância da influência dos diplomas. Isso significa que a influência dos diplomas é mais elevada quando o emprego é relativamente raro e as desigualdades escolares são grandes.

22 Construímos uma variável "macro" que expressa o dinamismo do marcado de trabalho pela associação de seis variáveis:

- média dos índices de emprego de 1995 a 2005 de 15 a 60 anos

- média dos índices de atividade de 1995 a 2005 de 15 a 60 anos

- média dos índices de emprego de 1995 a 2005 de 55 a 64 anos

- média dos índices de emprego das mulheres de 2000 a 2005

- média dos índices de desemprego de 1995 a 2005

- média dos índices de desemprego de longa duração (superior a 12 meses) de 1995 a 2005 
Quadro 1. Explicação estatística do nível de "influência"

\begin{tabular}{|c|c|c|c|c|}
\hline Modelo & & $\begin{array}{c}\text { Coeficientes não } \\
\text { padronizados }\end{array}$ & $\mathbf{T}$ & Significância \\
\hline & (constante) & 4 & & \\
\hline & Desigualdades escolares & $\mathbf{0 , 2 6 9}$ & 4,33 & 0,000 \\
\hline & $\begin{array}{c}\text { Dinamismo do mercado } \\
\text { de trabalho }\end{array}$ & $\mathbf{- 0 , 3 9 1}$ & $\mathbf{- 3 , 2 8}$ & $\mathbf{0 , 0 7 8}$ \\
\hline
\end{tabular}

Nota de leitura: os coeficientes "B" expressam os valores dos parâmetros da equação do modelo. Um sinal positivo (ou negativo) indica uma relação positiva (ou negativa) entre a variável explicativa e a variável a explicar (aqui, "influência"). Quanto mais elevado o valor de B, mais elevada a relação. Os valores nas colunas " $\mathrm{T}$ " e "significância" indicam se a variável independente considerada é verdadeiramente capaz de explicar as variações da variável dependente. Nesse caso, os valores de T devem estar fora do intervalo (-2; +2). Quanto mais elevados os valores de T, mais baixos os valores na coluna "significância", e mais estatisticamente significativa é considerada a relação entre a variável dependente e a variável independente. $O$ " $R^{2}$ ajustado" indica a parte de variância explicada pelo modelo. "Sig" indica a significância do modelo em seu conjunto. Nesse modelo, a variável dependente é a variável influência, e o R² ajustado é de 0,032 (33,2\% da variância da variável influência é explicado pelas variáveis consideradas (Sig $=0,003$ ).

\section{Configurações nacionais}

O modo de articulação dos diplomas com as posições sociais se inscreve em um conjunto de relações específicas a cada país. Alguns deles podem apresentar níveis de influência comparáveis por razões históricas, sociais ou econômicas muito diversas. Tomemos o caso dos países cujo nível de influência é pequeno. Na Suécia, isso remete a um nível relativamente baixo de desigualdades salariais e também a relações tradicionalmente distendidas entre o Estado, responsável pela educação e por uma formação profissional às vezes criticada justamente como acadêmica demais, de um lado, e o setor privado de outro (Erikson, Jonsson, 1998). Intervém também o fato de que os sindicatos, muito influentes nas convenções referentes às remunerações e carreiras, tendem a não privilegiar o critério do diploma para não dificultar a mobilidade profissional interna, embora lutem com eficácia por um leque de salários relativamente reduzido. 
O nível de influência pode ser relativamente alto em certos países por razões diferentes, até mesmo opostas. Em alguns países anglo-saxões, como o Reino-Unido ou os Estados Unidos, é a amplitude das desigualdades salariais, acima de tudo, que puxa para cima a variável influência (Arum, Hout, 1998; Heath, Cheung, 1998). Também há, principalmente do Reino-Unido, uma tradição de clivagem entre a formação geral e a formação profissional, que só ocorre após a formação inicial e frequentemente na própria atividade ("on the job"), organizada de maneira descentralizada e ratificada por uma grande quantidade de qualificações profissionais. Evidentemente, isso não favorece relações fortes entre os diplomas e os empregos, ainda mais que os jovens diplomados se inserem em uma gama de profissões bastante limitada para evoluir a seguir. Nos Estados Unidos, a educação e a formação são concebidas como um investimento individual e há poucas relações institucionalizadas entre as escolas e os empregadores; por outro lado, as formações escolares são diversas demais, bem pouco comparáveis e com uma hierarquia em escala nacional pouco nítida para que convenções estáveis rejam precisamente as relações entre os títulos e os postos. Como no Reino-Unido, a mobilidade profissional parece bastante forte nos primeiros anos, e talvez a vantagem dos diplomas seja apenas adiada.

Na Alemanha, a forte articulação entre os diplomas e as posições sociais se inscreve no sistema dual. Compreende-se então que os títulos escolares sejam valorizados. A existência de uma seleção precoce seguida de percursos escolares claramente hierarquizados contribui para dar aos diplomas um poder informativo claro sobre o valor dos candidatos. Isso anuncia uma forte influência dos diplomas no início da carreira posteriormente atenuada se a mobilidade profissional for importante. Frequentado pela maioria de uma faixa etária, o ensino profissionalizante torna as empresas privadas co-responsáveis pela formação dos jovens e pelo começo profissional, o que pode atenuar a influência dos diplomas em início de carreira. 
Esses poucos casos lembram que a atribuição dos indivíduos aos diversos lugares da sociedade nem sempre está sob o controle total da instituição escolar, o que apenas as teorias excessivamente centradas na escola puderam ignorar. Eles lembram também que não há nenhuma razão para atribuir ao modelo meritocrático mais abstrato um valor particular, já que esse princípio de justiça pode se voltar contra si mesmo, conforme mostra a amplitude da reprodução social que ele pode induzir quando as qualificações escolares têm uma espécie de monopólio na distribuição dos indivíduos. Nesse caso, encontramo-nos diante de um dos problemas de justiça evocado por M. Walzer (1997): as desigualdades desenvolvidas em uma esfera de atividade, por exemplo, a educação, só se tornam verdadeiramente injustas quando determinam "demais" as desigualdades desenvolvidas em uma outra esfera, tal como o trabalho; o inverso é igualmente verdadeiro.

Influência dos diplomas e reprodução social

A influência dos diplomas é o vetor de uma reprodução social mais ou menos pronunciada? Para testar essa hipótese, seria preciso criar um indicador empírico, necessariamente imperfeito, da noção bastante global de reprodução. Construímos a variável "reprodução", que mede o impacto do salário do pai no salário de seus filhos. Essa variável é, em modalidades diversas, muito explorada na literatura econômica (D'Addio, 2007). Geralmente é medida por meio da fração da diferença de renda existente em um dado momento entre todos os adultos que é transmitida aos seus descendentes; quanto maior for essa fração, maior será a reprodução da renda, no sentido da transmissão intergeracional, e menor será a mobilidade intergeracional da renda ${ }^{23}$. Em outras palavras, quanto

23 Os economistas utilizam o termo "elasticidade" (que, de maneira geral, designa a variação de uma variável em função de outra). Assim, e ao contrário do que deixaria entender intuitivamente a noção de elasticidade, quanto mais elevado for o valor desta, maior será a reprodução intergeracional. Escolhemos não retomar esse termo para evitar confusões. 
maior a reprodução no sentido aqui definido, mais encontradas nos filhos são as desigualdades entre adultos. A esse respeito, importantes variações distinguem os países da OCDE: menos de $20 \%$ da diferença entre os ganhos dos pais são transmitidos aos filhos em alguns países nórdicos, na Austrália ou no Canadá; a França tem uma taxa de 41\% contra aproximadamente $50 \%$ em países como Itália, Reino Unido ou Estados Unidos.

A transmissão das características sociais dos indivíduos de uma geração a outra depende em primeiro lugar do contexto social global, contrariamente ao que afirma a ideologia meritocrática, essencialmente individualista (Duru-Bellat, 2009). Na prática, se o país tem um forte crescimento, as jovens gerações têm acesso a um melhor nível de vida, e a estratificação se desloca para cima graças ao crescimento do número de empregos qualificados. Porém, também a educação desempenharia um papel importante, na medida em que a "mobilidade da renda" de uma geração a outra depende especialmente dos rendimentos da educação. A transmissão pais-filhos da renda seria mais marcada quando a educação fosse muito rentável, quando a influência escolar favorecesse a transformação das desigualdades escolares em posições sociais e, portanto, em desigualdades sociais. Nesse caso, estaríamos lidando com sociedades fechadas, nas quais os diplomas decidem muito cedo os destinos individuais.

Para testar essa hipótese, podemos partir do exame das correlações entre as variáveis reprodução, influência e desigualdades sociais. 
Quadro 2. Matriz de correlação entre "influência do diploma", "reprodução social" e "desigualdades escolares"

\begin{tabular}{|c|c|c|c|c|}
\hline & & $\begin{array}{c}\text { Influência } \\
\text { do diploma }\end{array}$ & $\begin{array}{c}\text { Reprodução } \\
\text { social }\end{array}$ & $\begin{array}{c}\text { Desigualdades } \\
\text { escolares }\end{array}$ \\
\hline \multirow{4}{*}{$\begin{array}{c}\text { Influência do } \\
\text { diploma }\end{array}$} & Coeficiente de correlação & 1 &, $745(* *)$ &, $327\left(^{*}\right)$ \\
\cline { 2 - 5 } & Sig. (bilateral) & &, 005 &, 096 \\
\cline { 2 - 5 } & $\mathrm{N}$ & & 12 & 27 \\
\hline \multirow{2}{*}{$\begin{array}{c}\text { Reprodução } \\
\text { social }\end{array}$} & Coeficiente de correlação & & 1 &, 460 \\
\cline { 2 - 5 } & Sig. (bilateral) & & & 132 \\
\cline { 2 - 5 } & $\mathrm{N}$ & & & 1 \\
\hline $\begin{array}{c}\text { Desigualdades } \\
\text { escolares }\end{array}$ & Correlação de Pearson & & & 12 \\
\hline
\end{tabular}

Nota de leitura: quanto mais o valor da correlação se aproximar dos valores extremos -1 e +1 , maior será a relação entre as variáveis. Os asteriscos indicam que a correlação é estatisticamente significativa (bilateral).

Duas correlações se revelam fortes e significativas. De um lado, encontramos a correlação entre as desigualdades escolares e a influência dos diplomas. De outro, e de maneira ainda mais nítida, a reprodução social, apreendida pelo fato de que a renda é transmitida de uma geração a outra, é muito forte e positivamente correlata $(R=0.745$; Sig $=0.005)$ da influência dos diplomas sobre o emprego. Quando os diplomas trazem grandes vantagens - variável influência -, a transmissão dos salários dos pais aos filhos é então mais marcada - variável reprodução. De modo recíproco, a transmissão das vantagens familiares - variável reprodução - é facilitada quando os diplomas trazem vantagens significativas - variável influência. A correlação evidentemente nada diz sobre o sentido dessa relação, mas podemos pensar que as estratégias de reprodução social pelo diplomas serão muito mais marcadas quando a influência destes sobre a situação profissional for importante.

O gráfico a seguir permite observar a posição dos países estudados sob essas duas dimensões. Assim, opõem-se um grupo de países nos quais 
a influência dos diplomas é baixa e a reprodução, pouco marcada (países do Norte da Europa, Austrália, Canadá), e países com características opostas (Estados Unidos, Itália, Reino Unido). Alguns, como a Alemanha ou a França, estão em uma posição menos típica: a reprodução é de amplitude moderada na Alemanha, apesar de uma influência bastante marcada dos diplomas, enquanto a França conjuga uma forte reprodução social com uma influência dos diplomas mais baixa.

Gráfico 6. Influência dos diplomas e reprodução social

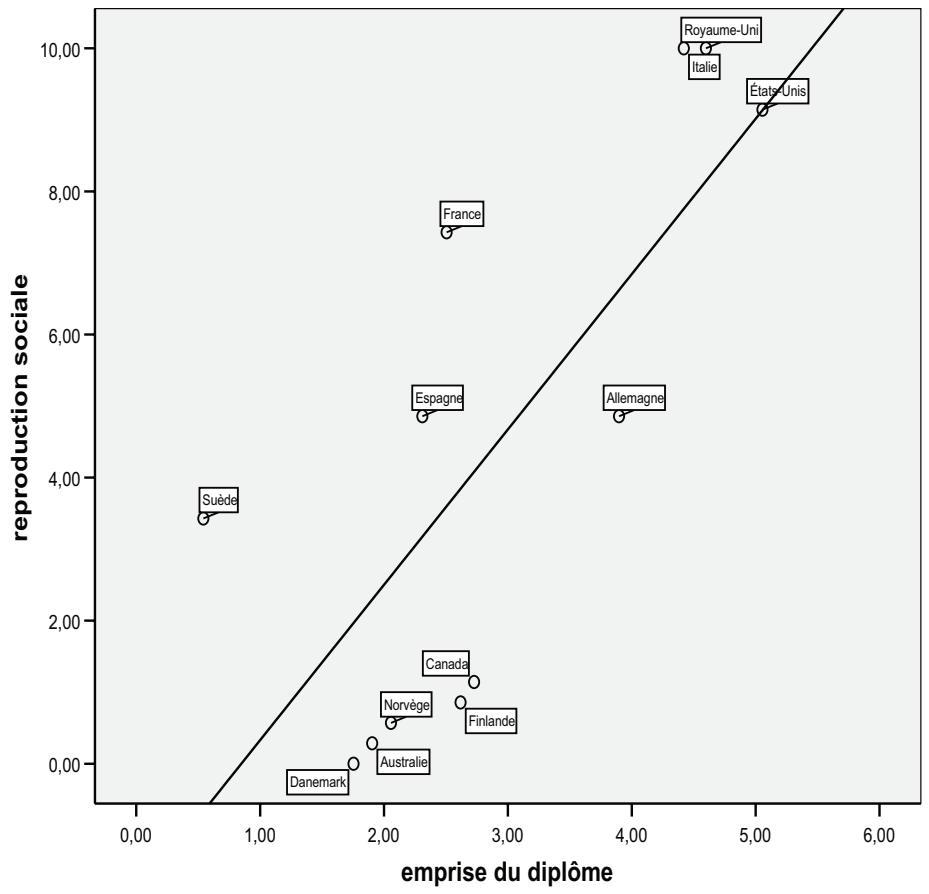

Nota de leitura: o gráfico classifica os países em função do indicador de influência dos diplomas e do indicador de reprodução social (transmissão intergeracional das rendas). 
Reprodução social e desigualdades escolares

Mesmo que a constatação possa parecer banal, é preciso atentar para a correlação positiva entre as desigualdades escolares e a força da reprodução social medida pela transmissão intergeracional da renda. De modo tendencial, quanto mais desigualdades escolares existirem, mais marcada, em média, será a reprodução social e mais as rendas serão transmitidas de uma geração a outra. Entretanto, essa correlação, embora elevada $(0,460$, enquanto não significativa, tendo em vista o pequeno número de países), está longe de ser automática, e a análise que antecede permite entender por quê. Mesmo quando existem grandes desigualdades escolares, se a influência dos diplomas for pouco marcada, isso não se traduzirá por uma reprodução social marcada. Neste caso, a transformação das posições escolares em posição sociais não é evidente, e a escola não é o agente hegemônico e total da reprodução. Mostramos aqui que não é possível entender a reprodução limitando-se ao mundo escolar: sem dúvida, a escola produz diplomas que importam, mas é indispensável levar em consideração a rentabilidade dos títulos escolares. 
Sociologias, Porto Alegre, ano 14, no 29, jan./abr. 2012, p. 22-70

Gráfico 7. Desigualdades escolares e reprodução social

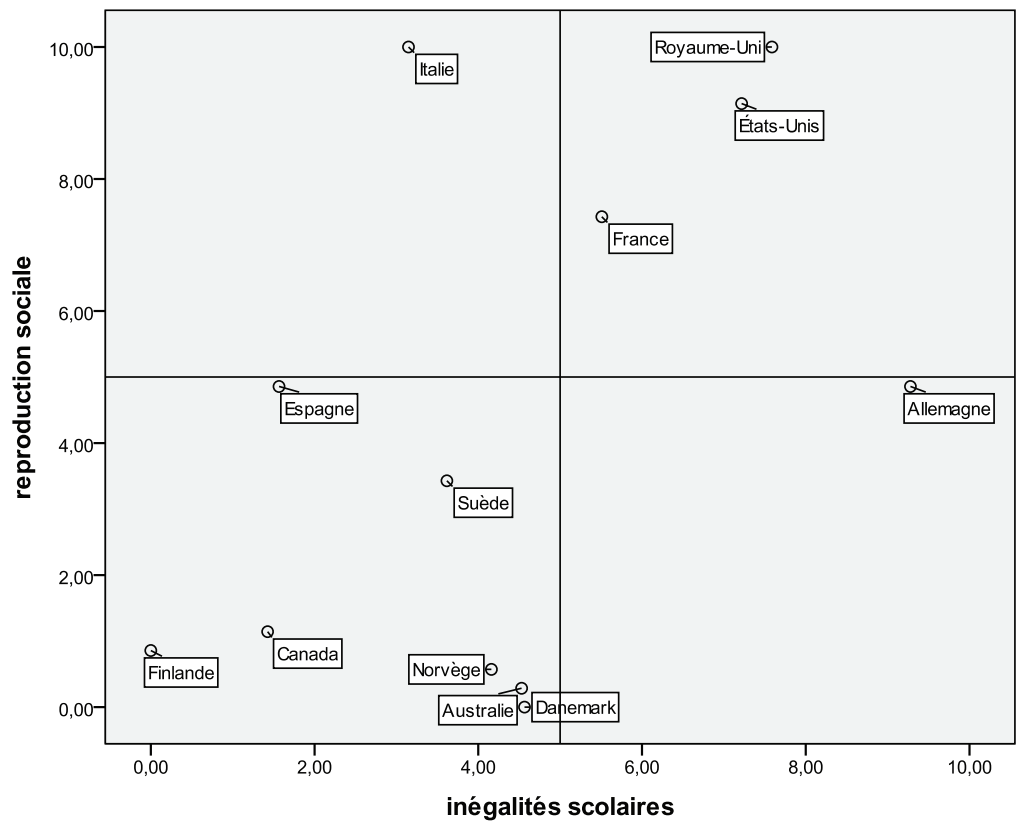

Nota de leitura: o gráfico classifica os países em função do indicador de desigualdades escolares (desigualdades de aquisição e desigualdades sociais entre alunos) e do indicador de reprodução social (transmissão intergeracional das rendas).

O gráfico ilustra uma tendência geral: quanto maiores forem as desigualdades escolares, maior será a reprodução e, portanto, mais as posições dos pais serão transmitidas aos filhos. Esse vínculo é particularmente marcado na França e, mais ainda, no Reino Unido e nos Estados Unidos. Nos lugares onde as desigualdades escolares são menores, há menos rigidez na estrutura social. Porém, existem exceções, como a Itália, que conjuga desigualdades escolares bastante pequenas e uma reprodução 
elevada, ou ainda a Alemanha, que conjuga, ao contrário, desigualdades escolares bastante marcadas e uma reprodução social de menor peso. Aqui, a escola não é uma correia de transmissão das desigualdades sociais.

Globalmente, o exame das correlações entre as variáveis desigualdades escolares/influência/reprodução esclarece o papel desempenhado pela escola na reprodução social. A influência dos diplomas aparece como o elo essencial: a reprodução social depende mais da influência escolar do que das desigualdades escolares (lembremos que as correlações são, respectivamente, de 0,745 e 0,460), pois, neste quesito, é da primeira que depende o alcance das segundas. Isso é confirmado quando cruzamos, em um modelo, todas essas dimensões para avaliar o seu peso relativo no processo global da reprodução das desigualdades de uma geração a outra: o coeficiente da variável influência é bem superior ao da variável desigualdades sociais, e apenas essa variável afeta significativamente a reprodução.

Quadro 3. Explicação estatística da variabilidade da variável "reprodução"

\begin{tabular}{|c|c|c|c|c|}
\hline Modelo & & Coeficientes não padronizados & T & Significância \\
\hline & & $\mathrm{B}$ & & \\
\hline & (constante) & $-2,167$ & $-1,039$ &, 326 \\
\hline & Influência dos diplomas & 1,981 & 2,740 &, 023 \\
\hline & Desigualdades escolares &, 199 & 0,555 &, 593 \\
\hline & & & & \\
\hline
\end{tabular}

Nota de leitura: aqui, a variável dependente é o indicador de reprodução social, o R2 ajustado é de 0,475 (Sig = 0,022), o que significa que $47,5 \%$ da variância da reprodução social assim mensurada são explicados pelas duas variáveis levadas em consideração. 
O fato de a influência ser a única variável significativa nos modelos que construímos sobre nossa amostra de países talvez se explique por sua grande variabilidade de um país a outro. Vários estudos mostram que a influência dos diplomas sobre a posição social varia bem mais do que as outras variáveis, especialmente a amplitude das desigualdades escolares, quando comparamos um conjunto de países (Shavit, Muller, 1998). Ou seja, os países globalmente comparáveis se distinguem menos por suas desigualdades escolares do que pelos níveis de influência dos diplomas sobre os empregos. Certamente, a vantagem trazida pelos diplomas é mais ou menos marcada, conforme mencionamos, de acordo com a amplitude das desigualdades de renda, que estabelece sua margem de ação, por assim dizer. Portanto, não nos surpreendemos ao constatar que o próprio saldo desses mecanismos, a força da reprodução social, varia segundo a amplitude das desigualdades de rendas. Como mostra o gráfico abaixo, existe, de fato, uma correlação positiva marcada ( $\mathrm{R}=0,684 ; \mathrm{Sig}=0,014)$ entre a amplitude das desigualdades de rendas e a força da reprodução: a reprodução social é muito mais acentuada quando as desigualdades de renda são importantes. 
Gráfico 8. Desigualdades de renda e reprodução social

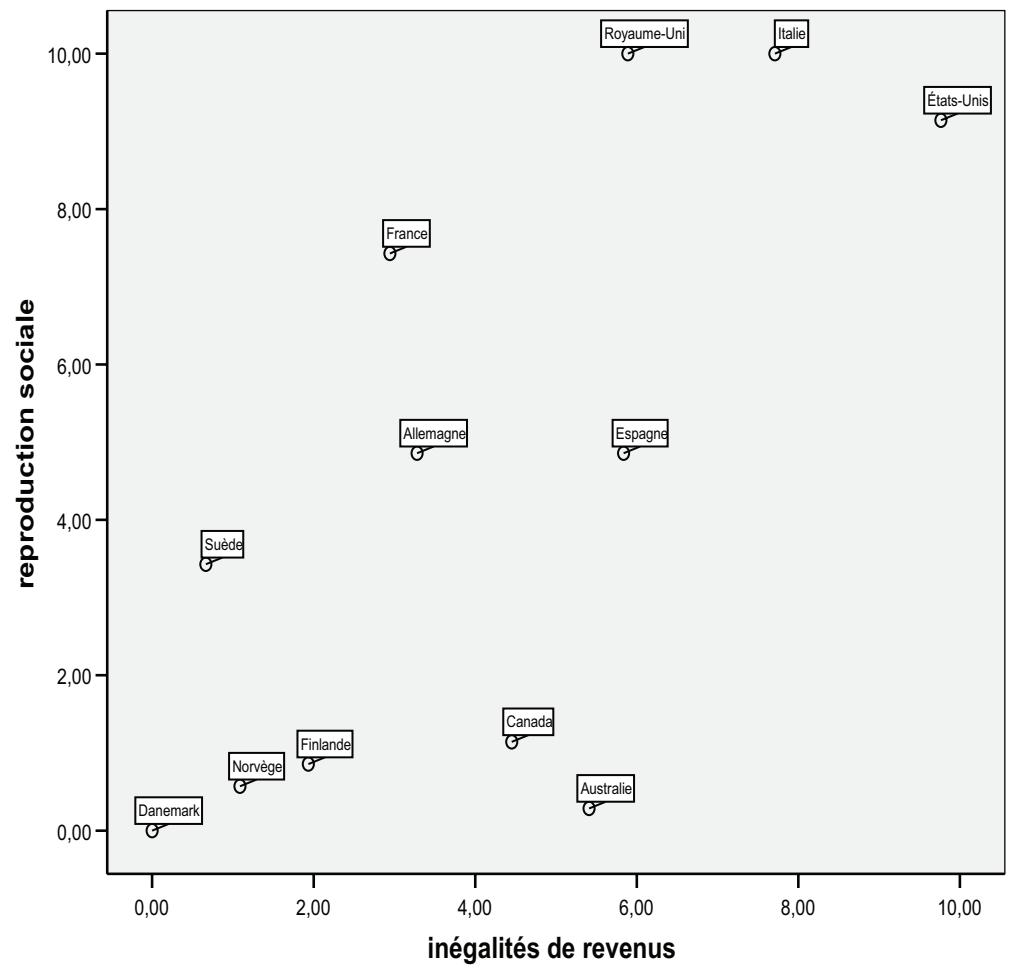

Nota de leitura: o gráfico classifica os países em função, de um lado, das desigualdades de rendas entre adultos (índice de Gini) e, de outro, em função do indicador de reprodução social. 
A correlação entre as desigualdades de renda e a força da reprodução social não é total: alguns países, como o Canadá ou a Austrália, conjugam grandes desigualdades de renda com uma reprodução social pouco marcada; outros, como a França, estão numa situação inversa, com uma reprodução social bastante forte sobre um pano de fundo de desigualdades de renda moderadas.

Três tipos de reprodução social

Resulta dessas análises que o mecanismo global da reprodução social varia sensivelmente de acordo com os países; não apenas a intensidade da reprodução varia entre eles, mas os próprios processos dos quais resulta essa reprodução jamais são exatamente idênticos.

O primeiro tipo puro é o da reprodução social. Conjugam-se então grandes desigualdades escolares, uma forte influência dos diplomas e, no fim das contas, uma alta reprodução. Os países mais próximos desse caso são os Estados Unidos e o Reino Unido. A Alemanha se aproxima deles com desigualdades escolares elevadas, uma influência que, nesta restrita amostra de doze países, é relativamente alta e uma reprodução média. A França também tende a esse tipo, com desigualdades escolares que não podem ser ignoradas e uma reprodução bastante alta, combinadas com uma influência média do diploma.

O segundo tipo puro é o da fluidez, caracterizado por efeitos pequenos das desigualdades sociais sobre as desigualdades escolares, por uma pequena influência e por pouca reprodução. As relações entre essas três dimensões são relativamente frouxas. Vários países se aproximam desse tipo, especialmente a Finlândia e o Canadá, seguidos, em posições mais distantes, por Austrália, Noruega e Suécia.

Por fim, o terceiro grupo típico é caracterizado pela desarticulação da educação e da reprodução. Neste caso, a reprodução é significativa, 
até mesmo alta, como no primeiro grupo, mas não passa pela escola. É o caso da Espanha, onde as desigualdades escolares, a influência dos diplomas e a reprodução são médias. Aqui, tudo se passa como se a sociedade quase não levasse em conta hierarquias escolares. O caso da Itália é ainda mais atípico e interessante: a reprodução social e a influência dos diplomas são elevadas, mas as desigualdades escolares são pouco significativas. Portanto, deve-se concluir levando-se em conta singularidades nacionais, e não combinações simples e automáticas de algumas variáveis.

Todas essas constatações têm certa coerência, e reencontramos aqui grandes tendências já apontadas pelos economistas e pelos sociólogos da mobilidade social: quando a influência da escola é grande, não apenas as desigualdades de carreiras escolares são importantes, mas também a reprodução é maior, aqui medida pela imobilidade da renda. Globalmente, trata-se de sociedades rígidas, onde a atribuição das posições é decidida por diplomas, eles próprios decididos pela origem social. Além dessas tendências médias, existem países relativamente atípicos que apresentam perfis bastante instrutivos. É o caso da Alemanha, onde as desigualdades escolares são grandes e a reprodução, moderada. Podemos cogitar a hipótese de que existem na Alemanha sistemas "compensadores", como a qualidade da formação profissional, que atenuam consideravelmente o efeito de rigidez e de influência das desigualdades escolares, sobre um pano de fundo de desigualdades de rendas moderadas. Graças a esses mecanismos, a sociedade acaba sendo mais justa do que a escola. De certa forma, podem existir compensações no outro sentido, e o caso da Itália é dos mais interessantes: neste país, as desigualdades escolares não são maiores do que na Suécia, mas a reprodução social é das mais rígidas. Podemos supor, então, que as desigualdades escolares, ainda que baixas, têm consequências sociais muito elevadas ou, mais provavelmente, que outras redes além da escola permitem reproduzir as posições sociais elas 
próprias bastante desiguais. Teríamos aqui um dos traços das sociedades dos diversos modelos "mediterrâneos", nos quais o capital social local, urbano e familiar é mais importante do que as instituições nacionais como a escola, ou um aspecto do capital social que caracteriza, segundo Putnam, a Itália meridional (Putnam, 1993). Em todos os casos, em oposição à Alemanha, a sociedade italiana seria menos justa do que a sua escola.

\section{Conclusão}

A sociologia da educação nos habituou a acreditar que "tudo se prepara" no período anterior à escola e a pensar que as desigualdades escolares são o mero reflexo das desigualdades sociais. Certamente, quando raciocinamos no nível dos indivíduos, essa percepção tem bastante fundamento: obtém-se muito mais êxito na escola quando se é oriundo das classes favorecidas. Porém, esse postulado pouco nos diz além disso, pois a amplitude das desigualdades escolares não é o "reflexo" mecânico da amplitude das desigualdades sociais quando se observam sociedades relativamente comparáveis. Para explicar variações bastante significantes, não se pode mais pensar apenas no que se passa antes da escola, e este artigo lembra que o que ocorre na escola atenua ou acentua o peso das desigualdades sociais sobre as desigualdades escolares. As escolas que selecionam tarde, que mantêm todos os alunos juntos e que individualizam as pedagogias parecem mais igualitárias e menos reprodutivas do que as outras. Essa constatação não é nova, mas merece ser lembrada.

Porém, para explicar as variações da amplitude e dos mecanismos da reprodução, também é preciso - e, talvez, sobretudo - se interessar por aquilo que se passa no período posterior à escola, especialmente pela maneira como os títulos escolares desigualmente distribuídos destinam os indivíduos a posições sociais igualmente desiguais. Vemos, então, que 
essa influência, muitas vezes baseada em argumentos de justiça meritocrática, retroage, ela própria, sobre as desigualdades escolares. Quanto maior for a influência, a utilidade social dos diplomas, maiores serão as desigualdades escolares. Não apenas as desigualdades escolares serão maiores, mas também a reprodução social será mais intensa: será mais elevada a parte da renda dos filhos explicada pela dos pais.

O método aqui apresentado prega uma inversão dos raciocínios clássicos da sociologia das desigualdades e da reprodução social. A reprodução intergeracional não deve ser percebida somente em função das características individuais das pessoas com a imagem da herança. Ela também depende dos "arranjos institucionais" pelos quais as sociedades canalizam seus membros nos sistemas escolares e, principalmente, depende da natureza das relações entre a escola e o emprego, apreendida por meio da influência dos diplomas (Kerckoff, 1995). Assim, somos levados a ultrapassar uma sociologia comparada dos sistemas educativos, tendendo para o que é então uma sociologia comparada da estratificação social.

Essa conclusão não tem apenas um interesse sociológico: tem também um alcance "político", na medida em que revela um dos paradoxos da crença nas virtudes democráticas e integradoras da escola. Quanto mais afirmamos que as desigualdades escolares são meritocráticas e justas, mais agimos para que elas assim o sejam, mais tentados estaremos a desenvolver a influência escolar. Porém, quanto mais aumentarmos essa influência, mais se aprofundarão as desigualdades escolares e mais se reproduzirão as desigualdades sociais, mostrando, mais uma vez, que o que vale para cada indivíduo não vale mais para a sociedade como um todo. Para criar uma escola mais justa, seria preciso, sem dúvida, agir não só no próprio funcionamento da escola, mas também agir no nível de influência das qualificações escolares, a fim de que as desigualdades escolares não determinem a totalidade dos percursos dos indivíduos. Seria necessário 
permitir que outros processos de formação, orientação e seleção deem novas oportunidades àqueles que falharam em suas chances escolares e impedir a escola de ter o monopólio da definição do mérito e do valor dos indivíduos. Na França, essa mudança de percepção dos mecanismos de formação e de reprodução das desigualdades seria quase uma revolução.

\section{Referências}

1. ADDIO (D'), A. International Transmission of Disadvantage: Mobility or Immobility Across Generations? OECD Social Employment and Migration Working Papers, 52, OECD Publishing, 2007.

2. ARUM, R.; HOUT, M. The early returns: the transition from school to work in the United States. In: SHAVIT, Y.; MÜLLER, W. From school to work. Oxford: Clarendon Press, 1998. p. 471-510.

3. BAUDELOT, C.; LECLERC, F. Les effets de l'éducation. Paris: La Documentation française, 2005.

4. BAUDELOT, C.; ESTABLET, R. L'élitisme républicain. Paris: Seuil, 2009.

5. BAYE, A.; DEMEUSE, M.; MONSEUR, C.; GOFFIN, C. Un ensemble d'indicateurs pour mesurer l'équité des 25 systèmes éducatifs de l'Union Européenne. Liège: Service de Pédagogie expérimentale, 2006.

6. BOURDIEU, P.; PASSERON, J. C. Les héritiers: les étudiants et la culture. Paris: Éditions de Minuit, 1964.

7. BOURDIEU, P.; PASSERON, J. C. La reproduction: éléments pour une théorie du système d'enseignement. Paris: Éditions de Minuit, 1970.

8. BREEN, R. (Ed.). Social Mobility in Europe. Oxford: Oxford University Press, 2004.

9. BROADFOOT, P.; MCNESS, E.; PLANEL, C.; RAVN, B.; TRIGGS, P. A World of Difference? Comparing Learners Across Europe. Maidenhead: Open University Press, 2003.

10. BUECHTEMANN, C.; VERDIER, E. Education and Training Regimes: macroInstitutionnal Evidence. Revue d'Economie Politique, 108, 3, p. 291-320, 1998.

11. CHAUVEL, L. Existe-t-il un modèle européen de structure sociale ? Revue de I'OFCE, 71, p. 283-298, 1999. 
12. DEMEUSE, M.; BAYE, A. Indicateurs d'équité éducative. Une analyse de la ségrégation académique et sociale dans les pays européens. Revue Française de Pédagogie, 165, p. 91-103, 2008.

13. DUBET, F. L'école des chances. Paris: Seuil, 2004.

14. DURU-BELLAT, M. L'inflation scolaire. Les désillusions de la méritocratie. Paris: Seuil, 2006.

15. DURU-BELLAT, M. Le mérite contre la justice. Paris: Presses de Sciences-Po, 2009.

16. DURU-BELLAT, M.; MINGAT, A. La constitution de classes de niveau par les collèges: les effets pervers d'une pratique à visée égalisatrice. Revue Française de Sociologie, XXXVIII, 4, p. 759-790, 1997.

17. DURU-BELLAT, M.; MONS, N.; SUCHAUT, B. Organisation scolaire et inégalités sociales de performance: les enseignements de l'enquête PISA. Education et Formations, 70, p. 123-131, 2004.

18. DURU-BELLAT, M.; MONS, N.; BYDANOVA, E. Cohésion scolaire et politiques éducatives. Revue Française de Pédagogie, 164, p. 37-54, 2008.

19. ERIKSON, R.; JONSSON, J. Qualifications and the Allocation Process of Young Men and Women in the Swedish Labour Market. In: SHAVIT, Y.; MÜLLER, W. From School to Work. Oxford: Clarendon Press, 1998. p. 369-406.

20. GOLDTHORPE, J. H. Problems of Meritocracy. In: ERIKSON, R.; JONSSON, J. (Eds.). Can Education Be Equalized? Boulder: Westview Press, 1996. p. 255-287.

21. GOLDTHORPE, J. H. The Myth of Education-Based Meritocracy. New Economy, 10 (4), December, p. 234-239, 2003.

22. GREEN, A. Le modèle de l'école unique, l'égalité et la chouette de Minerve. Revue Française de Pédagogie, 164, p. 15-26, 2008.

23. GREEN, A.; PRESTON, J.; JANMAAT, J. G. Education, Equality and Social Cohesion. New York: Palgrave MacMillan, 2006.

24. GROSS, M. Educational Systems and Perceived Social Inequality. European Societies, 5, 2, p. 193-225, 2003.

25. HEATH, A.; CHEUNG, S. I. Education and Occupation in Britain. In: SHAVIT, Y.; MÜLLER, W. From School to Work. Oxford: Clarendon Press, 1998. p. 71-102. 26. KERCKOFF, A. C. Institutional Arrangements and Stratification Processes in Industrial Societies. Annual Review of Sociology, 15, p. 323-347, 1995.

27. KERCKOFF, A. C. Transition from school to work in comparative perspective. In: HALLINAN, M. (Ed.). Handbook of the Sociology of Education. New York: Springer, 2000. p. 453-474. 
28. MAURICE, M.; SELLIER, F.; SYLVESTRE, J. J. Politiques de l'éducation et organisation industrielle en France et en Allemagne. Essai d'analyse societal. Paris: PUF, 1992.

29. MONS, N. Les nouvelles politiques éducatives. Paris: PUF, 2007.

30. MOORE, R. Back to the Future: the Problem of Change and the Possibilities of Advance in the Sociology of Education. British Journal of Sociology of Education, 17, 2, p. 145-161, 1996.

31. OCDE. Literacy Skills for the World of Tomorrow. Paris: OCDE, 2003.

32. PASSERON, J. C. L'inflation des diplômes: remarques sur l'usage de quelques concepts analogiques en sociologie. Revue Française de Sociologie, XXIII, 4, p. 551-584, 1982.

33. PASSERON, J. C. Hegel ou le passager clandestine. Esprit, 115, p. 63-80, 1986.

34. PETITAT, A. Production de l'école, Production de la société. Genève: Droz, 1982.

35. PFEFFER, F. T. Intergenerational Educational Mobility: comparative perspective. CDE Working Paper n²007-09, Madison, University of Wisconsin, 2007.

36. PFEFFER, F. T. Persistent Inequality in Educational Attainment and its Institutional Context. European Sociological Review, 24, 5, p. 543-565, 2008.

37. PERRY, L. Using PISA to examine educational inequality. Orbis Scholae, 2, 2, p. 77-86, 2008.

38. PUTNAM, R. D. Making Democracy Work. Civic Traditions in Modern Italy. Princeton: Princeton University Press, 1993.

39. SHAVIT, Y.; MÜLLER, W. From School to Work. Oxford: Clarendon Press, 1998.

40. TERRAIL J. P. L'école en France. Crises, Pratiques, Perspectives. Paris: La Dispute, 2005.

41. WALZER, M. Sphères de justice. Paris: Seuil, 1997.

Recebido em: 18/05/2011

Aceite final: 13/06/2011 